\title{
Faktor Exacta
}

Vol. 13, No. 2, June 2020, pp. 106-112

\section{Sistem Sortir Barang Otomatis Berbasis Arduino dengan Sensor Warna dan Monitoring via Android}

\author{
T. W. Wisjhnuadji ${ }^{1}$, Arsanto Narendro ${ }^{2}$, Pribadi Wicaksono ${ }^{3}$ \\ ${ }^{1,2,3}$ Fakultas Teknologi Informasi, Universitas Budi Luhur, Indonesia
}

Keywords:

Arduino

Android

Color Sensor

Infrared Sensor

ESP8266

\begin{abstract}
The Arduino-based sorting system is equipped with a color sensor and the monitoring of the number of goods via Android is a series of tools that serves to ease the work process of sorting goods by color manually at certain industrial companies. The method used to realize the problem above is by making a prototype of the sorting tool based on color automatically and monitoring the results of the sum of the items as connecting information from the device to Android. The tool is equipped with a TCS3200 color sensor as a color detector, an infrared sensor as an object counter, a DC motor and conveyor as a driving medium, a Servo motor as a sorting media, Arduino as a control media, and ESP8266 as a communication media and Android as a monitoring media. The results of test have been carried out on the prototype of this system, and are able to provide results in accordance with the design specifications of the tool.
\end{abstract}

Copyright $@ 2020$ Universitas Indraprasta PGRI. All rights reserved.

\section{Corresponding Author:}

T. W. Wisjhnuadji

Information Technology Faculty,

Universitas Budi Luhur,

J1. Ciledug Raya, Petukangan Utara, Kebayoran Lama, Jakarta Selatan.

Email: wisjhnuadji@budiluhur.ac.id

\section{PENDAHULUAN}

Untuk Meningkatkan kinerja produksi suatu perusahaan dapat dilakukan otomatisasi pada sistem pendukung produksinya. Untuk hasil produksi yang terdiri dari beberapa macam produk maka di dalam proses pengemasan pasti dilakukan pemilahan antar produk yang satu dengan produk yang lainnya. Untuk melakukan proses pemilahan produk dapat dilakukan baik secara manual atau pun secara otomatis dengan menggunakan mesin yang menerapkan teknologi pemilahan barang secara otomatis.

Untuk perusahaan yang berorientasi pada jenis perusahaan tradisional padat karya, maka proses pemilahan masih menggunakan cara manual, dengan tujuan untuk tetap dapat menyerap tenaga kerja sebanyak banyaknya. [1] Tetapi untuk perusahaan berskala besar dengan jumlah produksi dengan skala besar pula, maka sangat tidak efisien jika pemilahan barang dilakukan secara manual. Penggunaan konveyor sebagai bagian dari sistem pemilah dan penyortir barang sudah sangat umum digunakan. Diamana barang yang akan dipilah dilewatkan diatas konveyor, kemudian bararang tersebut harus melalui sensor sensor yang secara spesifik dapat melakukan deteksi terhadap parameter barang yang lewat, maka dengan bantuan sebuah prosesor yang diprogram untuk mampu memilah dan menyortir barang, maka disitu akan terjadi proses pemilahan, dimana pemilahan dapat saja berupa parameter dari warna benda, kalau demikian tentu ada sensor yang mampu untuk mendeteksi perbedaan warna benda, sehingga prosesor dapat mengambil keputusan, apakah benda tersebut akan dikumpulkan bersama benda lain yang memiliki kategori warna yang sama.[2].

\section{METODE}


Untuk membangun prototipe perangkat tersebut maka dilakukan perancangan dan pemodelan alat yang di dalamnya meliputi beberapa komponen yang berperan penting untuk dapat menjalankan semua fungsi di dalam sistem. Adapun modul modul pendukung yang diperlukan antara lain:

\subsection{Arduino Mega 2560}

Arduino Mega 2560 adalah papan pengembangan mikrokontroler yang berbasis Arduino dengan menggunakan chip ATmega2560. Papan ini memiliki pin I/O yang cukup banyak, sejumlah 54 buah digital I/O pin (15 pin diantaranya adalah PWM), 16 pin analog input, 4 pin UART (serial port hardware). Arduino Mega 2560 dilengkapi sebuah oscillator $16 \mathrm{Mhz}$, sebuah port USB, power jack DC, ICSP header, dan tombol reset. Dengan penggunaan yang cukup sederhana, Papan ini bisa menghubungkan power dari USB ke PC atau melalui adaptor AC/DC ke power jack DC. [3]

\subsection{MCU ESP8266}

ESP8266 merupakan Smart on Chip (SoC) Wi-Fi yang didesain berukuran minimalis dan hanya menggunakan sedikit rangkaian eksternal. Chip tersebut dapat berkomunikasi melalui infrastruktur Wi-Fi menggunakan protokol IPv4, TCP/IP, dan HTTP. Prosesor yang digunakan adalah seri Tensilica L106 Diamond dengan kecepatan 32-bit dan memiliki on-chip SRAM. Chip ini memiliki kemampuan untuk digunakan secara sendiri (standalone) atau menjadi access point untuk mikrokontroler. [4]

\subsection{Sensor Warna TCS3200}

Sensor warna TCS3200 rangkaian photodioda yang disusun secara matrik array $8 \times 8$ dengan 16 buah konfigurasi photodioda yang berfungsi sebagai filter warna merah, 16 photodioda sebagai filter warna biru, 16 photodioda sebagai filter warna hijau dan 16 photodioda lagi tanpa filter warna. [5]

\subsection{Motor Servo}

Motor Servo merupakan sebuah motor listrik dengan sistem umpan balik tertutup di mana posisi dari motor akan diinformasikan kembali ke rangkaian kontrol yang ada di dalam motor Servo. Motor Servo terdiri dari motor DC, serangkaian gear, potensiometer, dan rangkaian kontrol. [6]

\subsection{Motor DC}

Motor DC merupakan motor yang digerakkan oleh energi listrik arus searah. Salah satu jenis dari motor DC adalah motor DC magnet permanen. Sebuah motor DC magnet permanen disusun atas magnet permanen, kumparan jangkar, dan sikat (brush). Medan magnet yang besarnya konstan dihasilkan oleh magnet permanen, sedangkan komutator dan sikat berfungsi untuk menyalurkan arus listrik dari sumber di luar motor ke dalam kumparan jangkar. [7]

\subsection{Motor Driver L298N}

Modul driver ini didasarkan pada jembatan H L298N, dual full bridge driver yang berarus tinggi, bertegangan tinggi, dan diproduksi oleh perusahaan ST Company. Modul driver ini dapat mengontrol RPM motor dan arah rotasi motor. RPM dikontrol menggunakan input PWM ke pin ENA atau ENB, sementara rotasi arah dikendalikan dengan memasok sinyal high dan low ke EN1-EN2 untuk motor pertama atau EN3-EN4 untuk motor kedua. Driver Dual H-Bridge ini mampu bekerja hingga tegangan 46V. [8]

\subsection{Sensor Infra Red}

Infrared (IR) detektor atau sensor infra merah merupakan komponen elektronika yang dapat mengidentifikasi cahaya infra merah (infrared, IR). Sensor infra merah saat ini ada yang dibuat khusus dalam satu modul dan dinamakan sebagai IR Detector Photomodules. IR Detector Photomodules merupakan sebuah chip detektor inframerah digital yang di dalamnya terdapat fotodiode dan penguat (amplifier). [9]

\subsection{Switching Power Supply}

Switching Power Supply atau yang lebih dikenal dengan switched mode power supply (SMPS), adalah catu daya elekronika yang terdiri dari sebuah regulasi switching yang disediakan sesuai kebutuhan pada tegangan keluaran. Sebuah SMPS adalah daya pengubah yang meneruskan daya dari sebuah sumber untuk beban ideal tanpa rugi-rugi. Fungsi dari pengubah adalah untuk menyediakan tengangan keluaran pada level yang berbeda dibandingkan tegangan masukan. [10] 


\subsection{Modul Stepdown LM2596}

LM2596 suatu regulator yang berfungsi untuk menurunkan tegangan (step down). Regulator ini mampu mengeluarkan arus maksimal $3 \mathrm{~A}$, dengan daya input $3.5 \mathrm{~V}$ sampai $40 \mathrm{~V}$, dan daya output $1.2 \mathrm{~V}$ sampai $37 \mathrm{~V}$. Range tegangan input minimal $1.5 \mathrm{~V}$ lebih besar dari tegangan input. [11]

\subsection{Arduino IDE}

Arduino Integrated Development Environment (Arduino IDE) merupakan program khusus yang berjalan pada komputer yang memungkinkan untuk menulis sebuah program untuk papan Arduino. Sebuah kode program Arduino umumnya disebut dengan sketch. Arduino ditulis menggunakan bahasa pemrograman Java termasuk IDE-nya. [12]

\subsection{Android Studio}

Android Studio sebagai sebuah IDE (Integrated Development Environment) yaitu program komputer yang memiliki beberapa fasilitas yang diperlukan dalam pembangunan perangkat lunak. Android Studio merupakan pengembangan dari Eclipse IDE, dan dibuat berdasarkan IDE Java populer, yaitu IntelliJIDEA. [13]

\subsection{Proteus}

Proteus salah satu software simulasi rangkaian elektronika dan desain layout PCB. Dengan kata lain, software ini mengombinasikan antara menggambar skemtaik rangkaian, simulasi, dan desain layout PCB yang membantu dalam perancangan dan pembuatan rangkaian elektronika yang rumit. [14]

\subsection{Database MySQL}

MySQL merupakan salah satu software database (basis data) yang terkenal dan termasuk jenis RDBMS (Relational Database Management System) yang bersifat open source dan dikembangkan sebuah komunitas bernama MySQL dengan tujuan membantu user untuk menyimpan data dalam tabel-tabel. [15]

\subsection{Modul XAMPP}

XAMPP singkatan dari X (empat sistem operasi apapun), Apache, MySQL, PHP, dan Perl. XAMPP merupakan tool yang menyediakan paket perangkat lunak ke dalam satu paket. [16]

\section{HASIL DAN PEMBAHASAN}

\subsection{Perancangan Sistem}

Diagram blok dapat dilihat berdasarkan pada gambar 1. dengan beberapa komponen yang disertai dengan penjelasan masing-masing sebagai berikut:

1) Arduino Mega sebagai media pengendali dalam proses keseluruhan ini yang menjalankan proses data masukan dan data keluaran dari alat tersebut.

2) NodeMCU ESP8266 sebagai penyambung informasi agar bisa terhubung antara Arduino dan database melalui jaringan internet.

3) Sensor warna TCS3200 berfungsi sebagai pendeteksi barang berdasarkan warna.

4) Sensor Infrared kanan berfungsi sebagai pendeteksi dan penghitung barang yang sudah disortir di bagian kanan.

5) Sensor Infrared kiri berfungsi sebagai pendeteksi dan penghitung barang yang sudah disortir di bagian kiri.

6) Sensor Infrared kanan berfungsi sebagai pendeteksi dan penghitung barang yang sudah disortir di bagian tengah.

7) Motor Servo depan berfungsi sebagai palang penghalang di bagian depan untuk penyortiran barang.

8) Motor Servo belakang berfungsi sebagai palang penghalang di bagian belakang untuk penyortiran barang.

9) Motor Driver L298N berfungsi sebagai modul menggerakan komponen Motor DC

10) Motor DC digunakan sebagai media penggerak pada lintasan konveyor.

11) Aplikasi Android pada Smartphone yaitu perangkat yang sebagai media monitoring hasil data dari penjumlahan barang. 


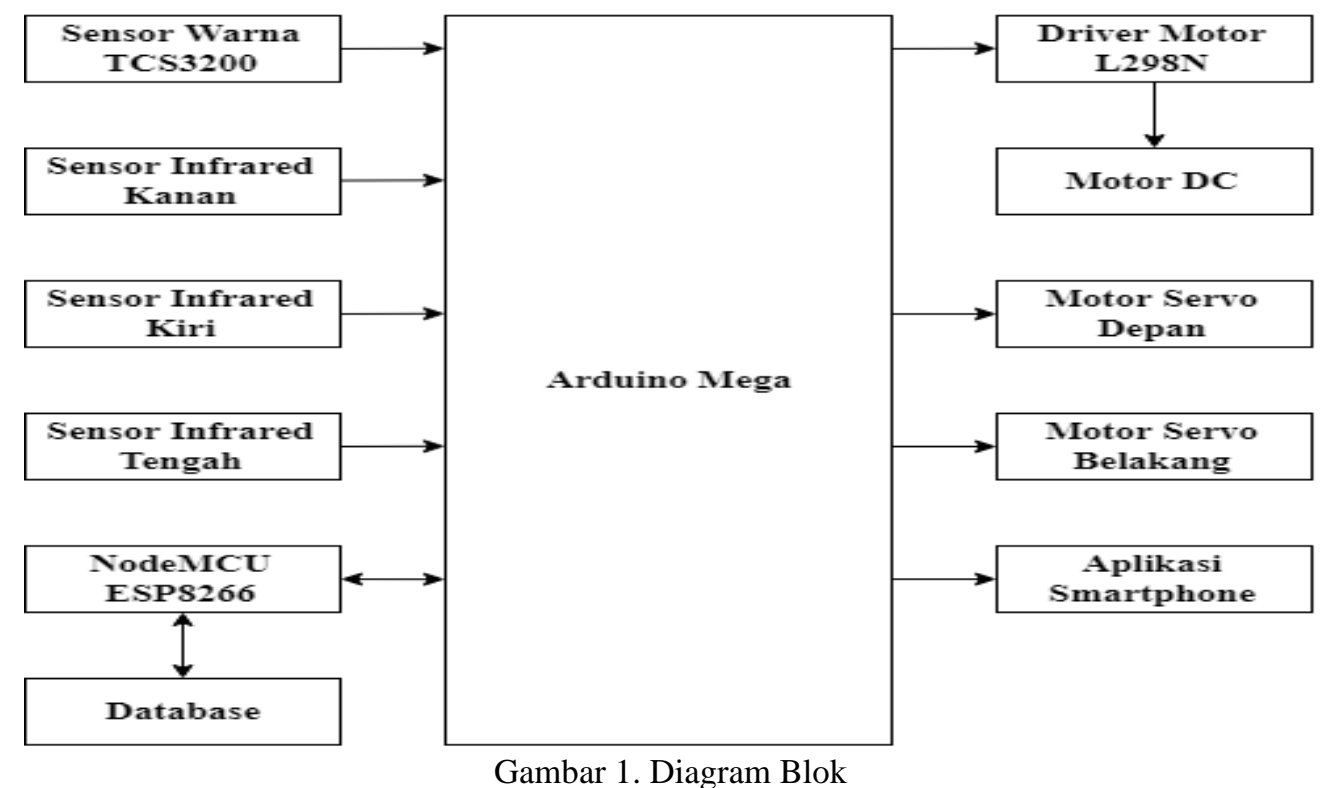

\subsection{Cara Kerja Alat}

Cara kerja dari sistem dapat dijelaskan melalui langkah langkah berikut:

1) Alat dari sistem sortir barang ini bekerja saat steker dicolokkan ke stopkontak untuk menghubungkan arus listrik dan kemudian bagian Blok Proses (Arduino Mega dan NodeMCU ESP8266) akan aktif serta motor DC akan aktif untuk menggerakan belt konveyor. Selanjutnya barang yang dibungkus warna-warni ditempatkan di atas konveyor. Barang tersebut pada saat ini akan memasuki tahap pertama, yaitu seleksi warna, pada tahapan ini barang akan melewati di atas konveyor dan dilanjutkan dengan proses pemindaian warna.

2) Prinsip kerja pada tahap pertama ini adalah konveyor utama yang sedang berjalan membawa barang tersebut terkena pancaran cahaya dari sensor warna TCS3200 di sisi samping konveyor. Sensor warna TCS3200 bekerja dengan cara membaca nilai intensitas cahaya yang dipancarkan oleh lampu LED yang sangat terang terhadap objek. Keluaran dari sensor warna ini yaitu berupa gelombang persegi dengan modulasi $50 \%$ yang dimana berbanding lurus dengan intensitas cahaya yang terbaca oleh sensor.

3) Saat semisal barang berwarna merah terkena pancaran cahaya dari sensor warna maka selanjutnya motor Servo 1 akan menutup di atas konveyor utama supaya barang tersebut disortir ke lintasan konveyor kanan, begitu pula bila semisal barang berwarna kuning terkena pancaran cahaya itu dengan motor Servo 2 juga akan menutup di atas konveyor utama lalu barang disortir ke lintasan konveyor kiri. Sementara bila semisal barang berwarna selain kedua warna tersebut maka barang tersebut tetap berada di atas konveyor utama.

4) Selanjutnya barang yang sudah disortir ataupun tidak disortir akan memasuki tahap kedua, yaitu menghitung barang. Pada tahapan ini barang akan melewati di atas konveyor masing-masing dan dilanjutkan dengan proses penjumlahan barang. Prinsip kerja pada tahap kedua ini adalah konveyor yang sedang berjalan membawa barang tersebut terkena pancaran cahaya dari sensor infrared di atas konveyor masing-masing.

5) Sensor infrared bekerja ketika cahaya infra merah diterima oleh fototransistor maka basis fototransistor akan mengubah energi cahaya infra merah menjadi arus listrik sehingga basis akan berubah seperti saklar (switch closed) atau fototransistor akan aktif (low) secara sesaat. Sensor infrared berjumlah sebanyak 3 buah yang terpasang di atas konveyor masing-masing, sensor infrared 1 berada di atas konveyor kiri, sensor infrared 2 berada di atas konveyor utama, dan sensor infrared 3 berada di atas konveyor kanan.

6) Saat barang tersebut terkena pancaran cahaya dari sensor infrared maka sensor infrared menghitung jumlah barang yang sudah disortir lalu disimpan ke database dan setelah itu barang tersebut akan ditempatkan ke wadah masing-masing. Selanjutnya hasil informasi yang sudah tersimpan di database akan muncul di layar Smartphone Android sebagai hasil monitoring jumlah barang. Oleh karena itu, 
penulis akan melakukan pengujian alat tersebut dengan membawa barang sebanyak 30 buah, 10 buah untuk barang merah, 10 buah untuk barang kuning, dan 10 buah untuk barang biru.

\subsection{Diagram Alir Sistem}

Diagram Alir dari sistem yang dibuat dapat dilihat pada gambar 2. dengan prosedur penjelas di bawah ini:
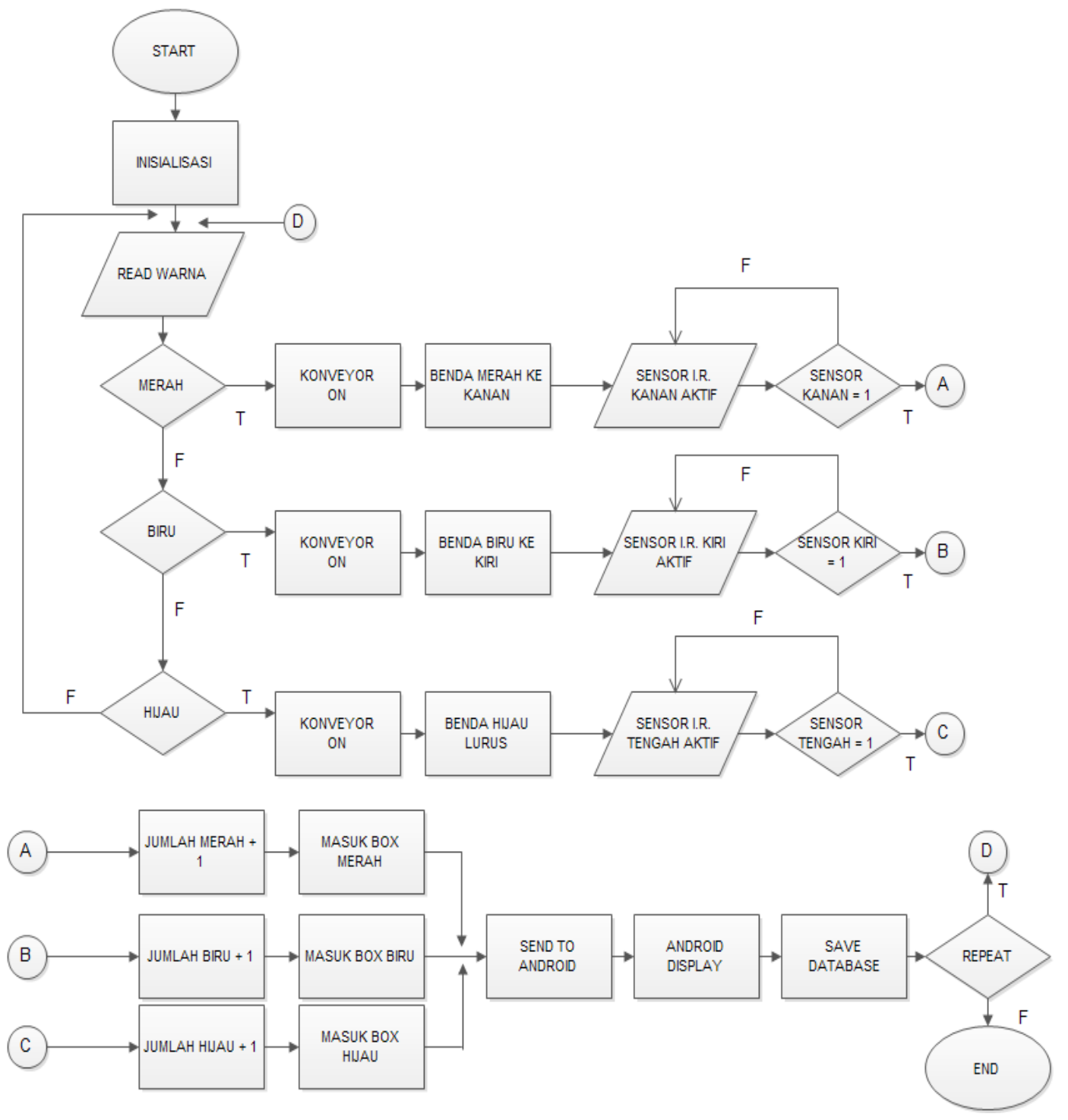

Gambar 2. Diagram Alir Sistem

1) Mulai Start, yaitu awal ketika sistem dihidupkan

2) Inisialisasi, yaitu ketika prosesor melakukan pemeriksaan dan persiapan awal semua perlengkapan pendukung sistem.

3) Sensor Warna Membaca, yaitu proses ketika Barang diletakkan pada conveyor, dan sensor warna mulai aktif.

4) Sensor Warna Merah, mendeteksi benda berwarna merah, dan meneruskan berjalan melalui konveyor menuju kotak Merah. Detektor penghitung menaikkan counter +1

5) Sensor Warna Biru, mendeteksi benda berwarna merah, dan meneruskan berjalan melalui konveyor menuju kotak Biru, Detektor penghitung menaikkan counter +1 
6) Counter +1 , barang akan bertambah satu jika ada benda dengan warna tertentu terdeteksi sesuai dengan warnanya, kemudian barang tersebut akan masuk kedalam box atau kotak penyimpanan sesuai dengan warna yang terdeteksi oleh sensor.

7) Total Barang dengan warna tertentu disimpan dalam database. Dan ditampilkan dalam monitor android. Total Barang dari masing masing warna kana ditampilkan didalam smartphone android sebagai informasi banyaknya barang dengan warna warna tertentu yang telah terkumpul setelah melalui proses sortir warna.

8) Jika amasih akan melanjutkan dengan proses sortir barang, maka akan dilakukan pengulangan ( $r e$ peat), dimana proses pembacaan warna oleh sensor diulang kembali

\subsection{Prototipe}

Prototipe yang dihasilkan adalah seperti yang terlihat pada Gambar 3. di bawah ini:

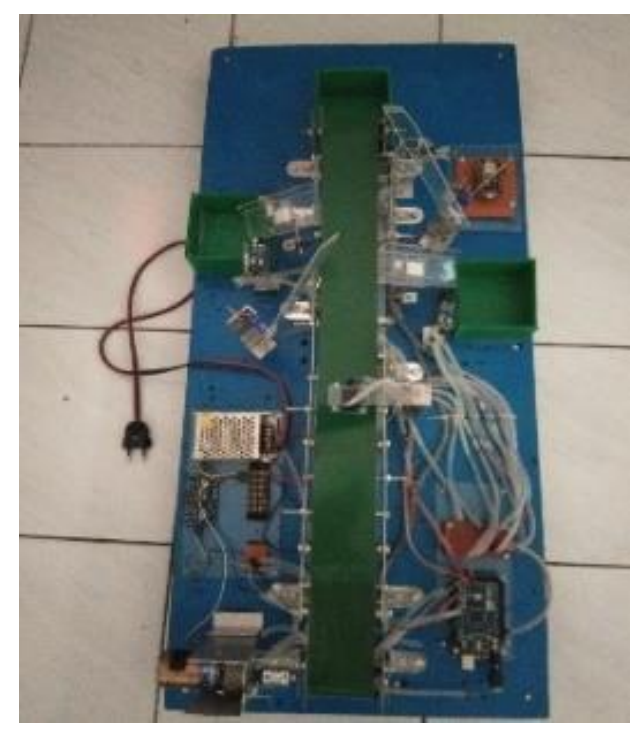

Gambar 3. Prototipe Sistem

Sedangkan tampilan pada smartphone android hasil perhitungan jumlah barang dengan warna tertentu, yaitu Merah, Biru dan Hijau dapat dilihat pada Gambar 4 di bawah ini.

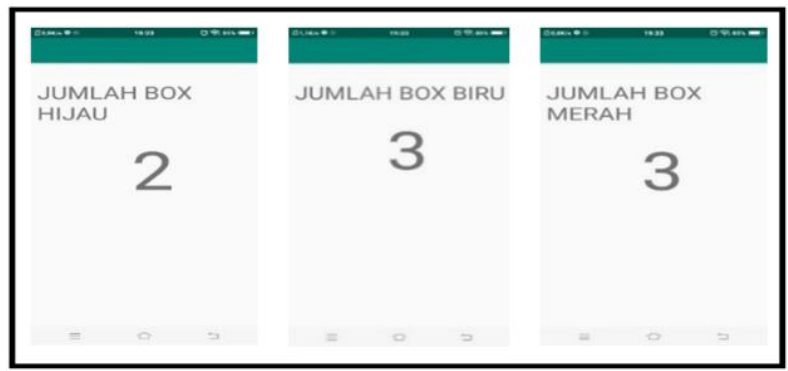

Gambar 4. Tampilan Smartphone Android

\section{PENUTUP}

Berdasarkan hasil pengujian yang telah dilakukan, maka dapat ditarik kesimpulan sebagai berikut ini Motor Driver L298N mampu bekerja dengan baik dalam mengatur putaran Motor DC. Sensor warna TCS3200 mampu bekerja dari proses pendeteksian sesuai yang ditetapkan pada program tersebut. Motor Servo mampu bekerja sesuai dengan harapan, dalam hal ini dapat menyortir barang yang sudah erdeteksi. Sensor Infrared mampu bekerja sesuai dengan harapan, dalam hal ini dapat menghitung barang yang sudah disortir masing- 
masing. Aplikasi Android pada Smartphone dapat bekerja sesuai dengan harapan yang mampu berkomunikasi melalui NodeMCU ESP8266 dengan alat tersebut

\section{DAFTAR PUSTAKA}

[1] A. D. B. Tarigan and I. Setiono, "Rancang Bangun Sistem Kendali Alat Penyortir Barang Berwarna Merah Dan Hijau Dengan Sensor Tcs230 Berbasis Plc Schneider,” Gema Teknol., vol. 20, no. 1, p. 17, 2018.

[2] M. Eriyadi and I. F. Fauzian, "Desain Prototipe Mesin Sortir Barang Otomatis," JTERA (Jurnal Teknol. Rekayasa), vol. 4, no. 2, p. 147, 2019.

[3] H. Muhammad, "Sistem Monitoring Infus Menggunakan Arduino Mega 2560," Universitas Islam Negeri Alauddin, 2017.

[4] H. Artanto, "Trainer Iot Berbasis Esp8266 Sebagai Media Pembelajaran Mata Kuliah Komunikasi Data Dan Interface Di Program Studi Pendidikan Teknik Elektronika Uny Tugas," Universitas Negeri Yogyakarta, 2018.

[5] N. S. Silalahi, "Alat Penyortir Buah Jeruk Menggunakan TCS3200 Berbasis Arduino Uno," Universitas Sumatera Utara, 2017.

[6] M. F. Wicaksono and Hidayat, Mudah Belajar Mikrokontroler Arduino Disertai 23 Proyek, termasuk Proyek Ethernet dan Wireless Client Server. Bandung: Informatika, 2017.

[7] Buntarto, Dasar-Dasar Kelistrikan Otomotif. Yogyakarta: Pustaka Baru Press, 2015.

[8] S. N. Octavianus, "Rancang Bangun Simulasi Pengendali Kursi Roda dengan Menggunakan Komunikasi Bluetooth Berbasis Arduino Nano," Universitas Sumatera Utara, 2018.

[9] F. Malau, "Rancang Bangun Sistem Antrian Pada TPS Berbasis Atmega16," Universitas Sumatera Utara, 2017.

[10] I. M. Arifana, "Rancang Bangun Power Supply Switching Dengan Proses Elektropleting Logam," Universitas Islam Negeri Maulana Malik Ibrahim, 2016.

[11] Y. Fazriati, "Simulasi Sistem Irigasi Otomatis Pada Tanamanam Padi Menggunakan Modul Mikrokontroler Arduino Dan Modul Gprs," Universitas Sumatera Utara, 2018.

[12] Nasution and A. Fauzi, "Perancangan Mobil Robot Pemberi Pakan Unggas Ayam Berbasis Arduino Uno Atmega 328P dengan Sistem Kendali Smartphone Android," Universitas Sumatera Utara, 2017.

[13] A. Fadilah, "Rancang Bangun Mobil Remote Control dengan Smartphone Android Menggunakan Sensor US-016 Berbasis Arduino Uno," Universitas Sumatera Utara, 2017.

[14] M. Syahwil, Panduan Mudah Belajar Arduino Menggunakan Simulasi Proteus. Yogyakarta: Andi Offset, 2017.

[15] Muhammad fatih hizbul islam, "SMART ROOM CONTROL ( SRC ) PADA RUANG SERVER BERBASIS ANDROID," Institut Bisnis dan Informatika STIKOM, 2018.

[16] Miono, "Perancangan sistem informasi dan aplikasi pengelolaan barang kios f-three dengan teknologi berbasis web xampp," Universitas Sebelas Maret, 2013. 